\title{
DOES ACCESS TO CREDIT IMPROVE HOUSEHOLD WELFARE IN THE LONG-RUN?
}

\author{
Hao Manh Quach \\ Lincoln Business School, University of Lincoln, UK.
}

\begin{abstract}
The positive relationship between access to credit and household welfare has been well explored and documented in the literature. The literature however sees just few research papers about Vietnam. One issue with most research papers in this area however is that while the conclusions are consistent, they mostly draw their findings from the analysis of cross-section data obtained from household surveys. Such an analysis represents a snapshot view and does not tell us much about the long-term impact of access to credit on household welfare. In this paper, we develop an econometric framework to test the impact of access to credit on household welfare in the long-run using data from two household surveys in Vietnam. The first survey covers a sample of 4,799 households, 150 communes and 300 villages over the country. The second survey, taken after 5 years, covers a sample of 5,999 households, 194 communes and 388 villages, including all households surveyed in the first survey. Our econometric framework considers and controls for the effect of endogenous credit and of the sample selection bias. We employ a three stage regression: the first stage controls for the sample selection bias; the second stage controls for the endogeneity of credit; and the third stage is to estimate the impact of access to credit on household welfare, where the inverse Mill's ratios and the predicted residuals, which are computed from the first and second stages, are included as explanatory variables. We find that access to credit has a positive and significant longterm impact on household welfare in terms of per capita expenditure, per capita food expenditure and per capita non-food expenditure. We also find that although both formal and informal credit contribute to household welfare, formal credit has a relatively higher impact than its informal counterpart. Our findings imply some policy recommendations. On the one hand, the findings encourage policies that improve the access to credit for poor households in rural areas. On the other hand, the low level of impact suggests that the subsidized credit should be reconsidered.
\end{abstract}

JEL Classifications: Q14, O16, and O18

Keywords: access to credit, microfinance, household welfare, Vietnam. Contact author's email address: $\underline{\mathrm{HQuach} @ \text { lincoln.ac.uk }}$ 


\section{INTRODUCTION}

The relationship between access to finance and household poverty reduction has been well explored in the literature. Evidence on the positive impact could be seen from pioneer research studies such as Khandker (1998, 2001, 2003), Pitt and Khandker (1998), Coleman (2002) etc or from more recent studies such as Karlan and Zinman (2010), Augsburg et al (2014), Angelucci et al (2015), Banerjee et al (2015) .etc.

The literature sees just few research papers about Vietnam. Among the few, Lensink and Pham (2012) find positive impact of access to credit and of the accumulated amount of credit on self-employment profits in Vietnam. Doan et al (2014) suggest that access to formal credit leads to positive impact on household's spending on education and healthcare while the informal credit does not. Or recently, Tran et al (2015) find that access to credit helps increase household income by $30 \%$ for the poor household as compared to the average household income, and that the formal credit plays more important role in this impact. Nghiem et al (2012), using a quasi-experimental study on households of microfinance programs by NGOs, however find that there is no significant impact of participation on household welfare proxied by income and consumption per adult equivalent. Other papers focus on the demand for credit or credit rationing, such as Pham and Izumida (2002) and on the use of credit such as Barsland and Tarp (2008) who find that formal credit is used mostly for production and asset accumulation while formal credit is for consumption smoothing.

While the conclusions are consistent, almost all of the above-mentioned papers draw their findings from analysis of cross-section data obtained from household surveys. Such an analysis represents a snapshot view and does not tell us much about the longterm impact of credit on household welfare. It is possible that, if we consider a borrowing household at a specific time $t$ only, this household may generate higher economic welfare because at time $t$ the economic condition is better, rather than because that credit has improved its welfare. In general, it may well be the case that the single-period impact of credit on household welfare is temporary, rather than persistent, or spurious.

This paper develops an econometric framework to investigate the long-term impact of credit on household welfare in Vietnam, using panel data. We seek to establish whether (or not) the changes in household welfare are correlated with changes in household borrowing in the long term.

The remainder of this paper is organised as follows. In Section 2, we develop an econometric framework for panel data analysis. Data characteristics and construction of variables are discussed in Section 3. Section 4 presents the empirical results and considers their implications. The concluding remarks summarise the key findings of the paper.

\section{THE MODEL}

\section{The baseline model}

We motivate our model by considering a household $i$ in village $j$ who borrows at both times, $t$ and $t+1$. At a certain time $t$, denote $c_{i j t}$ as the accumulative amount of credit that this household has borrowed by time $t$ and $y_{i j t}$ as an economic welfare that the household 
obtains at time $t$. The reduced form of the household borrowing and household welfare function are as follows:

$$
\begin{aligned}
& c_{i j t}=\beta_{0}^{c}+x_{1 i j t}^{\prime} \beta_{1}^{c}+x_{2 i j t}^{\prime} \beta_{2}^{c}+x_{3 i j t}^{\prime} \beta_{3}^{c}+w_{c i j}^{\prime} \beta_{w}^{c}+\varepsilon_{i j t}^{c} \\
& y_{i j t}=\beta_{0}+x_{1 i j t}^{\prime} \beta_{1}+x_{2 i j t}^{\prime} \beta_{2}+x_{3 i j t}^{\prime} \beta_{c}+w_{i j}^{\prime} \beta_{w}+\varepsilon_{i j t}^{y}
\end{aligned}
$$

where $x_{1}$ is a vector of household characteristics; $x_{2}$ is a vector of local market characteristics; and $x_{3}$ is a vector of lender characteristics; $w$ is a vector of unobservable characteristics of the household and local markets that may affect $c_{i j t}$ and $y_{i j t .} \varepsilon_{i j t}$ and $\varepsilon_{i j t}$ are mean-zero stochastic errors. The parameters of interest are $\beta_{i}{ }_{i}(i=0,1,2,3)$ and $\beta_{i}$ $(\mathrm{i}=0,1,2, \mathrm{c})$.

The household characteristics include the natural attributes such as the age of the household head, the gender of the household head and the household endowment such as the education of the household head, the ownership of land and household savings. The local market characteristics include the proxy variables representing the local economy such as the prices of the selected goods and services or the competitive advantage of the local market such as the average ownership of land, the average education of household head. The lender characteristics include the type of lenders: formal and informal and the availability of formal and informal funds.

\section{Endogenous credit}

With cross-section data, the endogeneity of credit arises for a number of reasons (see, for examples, Pitt and Khandker, 1998; Khandker and Faruque, 2002). First, the nonrandom allocation of credit may lead to biased estimation of the impact of credit on household welfare. The lender may screen applicants based on their characteristics. It is likely that the credit is distributed to better-off households, but better-off households generally are considered to be able to generate higher welfare. Also, the lenders may allocate more credit to some targeted markets, for example to poorer villages (e.g. lenders offer loans in compliance with a poverty reduction strategy or a regional development policy). It may be that borrowing households in poorer villages generate lower welfare than the non-borrowing households in better-off villages. Hence, the comparison of the credit impact on borrowing and non-borrowing households may be misleading. This type of bias was widely documented in the econometric literature, such as Heckman (1974, 1979), but in the literature of access to credit it was initiated with Pitt and Khandker (1998) and Coleman (1999).

In addition, the unobservable characteristics of households and local markets affect both the household borrowing, $c_{i j t}$, and the household welfare, $y_{i j t}$. In other words, the error terms, $\varepsilon_{i j k}^{c}$ and $\varepsilon_{i j k}$, are likely to be correlated. These unobservable characteristics may include preference heterogeneity, dedication and special effort exerted by households, or the competitive advantages of the local markets. It is possible that a household with greater preference, dedication or effort is more willing to borrow than others, and then is more capable to generate higher welfare than others. Thus, we may see that the generated economic welfare might not result from the increased borrowing, but from the fact that some households are more dedicated or hard-working than others. The 
estimation of the impact of credit on household welfare is therefore inconsistent (see Pitt and Khandker, 1998).

With panel data, households are observed at some points in time, e.g. at $t$ and $t+1$. As a result, the problem of endogeneity of credit is reduced to some extent (Khandker , 2003). If we consider the welfare function (2) at two points in time and take the difference, the unobserved characteristics are likely to be eliminated. The underlying assumption for this argument to be true and also for the estimation to be consistent is that the unobservable characteristics hardly change from $t$ to $t+1$. More specifically, it is expected that the preference heterogeneity, dedication and effort exerted by a household are constant over time. The reduced forms of the household borrowing and household welfare equations using panel data are as follows:

$$
\Delta c_{i j t}=\beta_{0}^{\Delta c}+\Delta x_{1 i j t}^{\prime} \beta_{1}^{\Delta c}+\Delta x_{2 i j t}^{\prime} \beta_{2}^{\Delta c}+\Delta x_{3 i j t}^{\prime} \beta_{3}^{\Delta c}+\varepsilon_{i j t}^{\Delta c}
$$

$$
\Delta y_{i j t}=\beta_{0}^{\Delta}+\Delta x_{1 i j t}^{\prime} \beta_{1}^{\Delta}+\Delta x_{2 i j t}^{\prime} \beta_{2}^{\Delta}+\Delta c_{i j t} \beta_{c}^{\Delta}+\varepsilon_{i j t}^{\Delta y}
$$

where $\Delta x_{l i j t}=x_{l i j t}-x_{1 i j t-1} ; \Delta x_{2 i j t}=x_{2 i j t}-x_{2 i j t-1} ; \Delta x_{3 i j t}=x_{3 i j t}-x_{3 i j t-1} ; \Delta c_{i j t}=c_{i t k}-c_{i j t-1}$; the parameters of interest are $\beta^{\Delta c_{i}}(\mathrm{i}=0,1,2,3)$ and $\beta^{\perp}{ }_{i}(\mathrm{i}=0,1,2, \mathrm{c})$.

Although the panel data may reduce the possibility of endogeneity of credit resulting from the unobservable characteristics of household and of the local market, it does not control for the non-random allocation of credit. It is still possible that credit is available and allocated more to households in poorer villages in both time $t$ and $t+1$. We may think of the fact that such strategies as poverty reduction and regional development target the same markets in both times, $t$ and $t+1$. The non-random allocation of credit causes the possibility of endogeneity of credit as it does with cross-section data. Moreover, we have assumed that unobservable characteristics of households and local markets are time invariant, but it may not always be the case. Therefore, the estimation of (4) using panel data is possibly biased, and results in inconsistent coefficients (for similar comments, see Khandker, 2003).

The econometric solution to this problem is to use instrumental variables in a two-stage regression method. The idea of using instruments is that we find variables that are well-correlated with household borrowing $c_{i j t}$, but are not correlated with household welfare $y_{i j t}$. In the first stage regression, the instruments are used to estimate the values of household borrowing that are not affected by household characteristics. In the second stage, the estimated values are used instead of household borrowing to correct for the endogeneity of credit. The equivalent is to use the estimated residuals together with household borrowing in the second stage. The significance of the estimated residuals indicates whether or not the instruments and the two-stage regression are appropriate. We construct and apply the Durbin-Wu-Hausman test (Hausman, 1978) for this purpose.

Selecting instrumental variables is not a trivial task. Pitt and Khandker (1998) use the exogenous loan eligibility criteria that a lender employs to select a borrower as the instrument. Such exogenous properties are appropriate for credit program assessment where they have specific selection criteria for the participants. Khandker (2003) uses the characteristics of the competitors as the instruments. His idea is that given a limited supply of funds, what matters is the allocation of funds by the lenders. The amount of credit that a household borrows depends not only on its own characteristics, but also on 
the characteristics of the competitors. The competitors may be at village level as well as district level where they influence the amount of credit that a particular household receives, but not the household welfare.

We follow Khandker's idea in the sense that the availability of funds is an important factor that affects the amount of credit that one household may receive, but not the household welfare. However, we consider the availability of funds and the competition between the informal and formal lenders in the village and commune to which the households have access, rather than in the village and commune of the competitors. The idea is that the amount of credit that one household can borrow is dependent on the amount of credit available in the village and commune. Moreover, if the households have access to both formal and informal sources of funds, the amount of household borrowing may be affected by the choice of where to borrow from since the households apparently choose between the two lenders. Alternatively, the amount of credit that a lender allocates a borrower may depend on the availability of credit from its competitor.

\section{Sample selection bias}

In order to gauge the impact of consecutive borrowing on household welfare, we are interested in the sample of households who borrow at time $t$. At time $t+1$, there are two sub-samples: (i) households who borrow at both times, $t$ and $t+1$; and (ii) households who borrow at $t$ but not at $t+1$. For convenience, if a household borrows at both times $t$ and $t+1$, it is called "participant household"; otherwise, it is called "non-participant household".

If we take the sample of participant households only and estimate the credit impact using the two-stage regression procedure, the results may suffer from sample selection bias. The reason is that the households who are non-participant households are possibly excluded for some reasons such as their self-selection or the exclusion by the lender, especially if the lender learns about a borrower's credit worthiness during the first period. If so, the results are inconsistent or at least less interesting since we do not know what would happen to the welfare of the non-participant households if they had chosen to borrow. The micro econometric analysis below will show how the selection bias matters and how we control for it. For convenience, we denote:

$$
\begin{aligned}
& y_{i}=\Delta y_{i j t} ; \\
& x_{l i}=\left(\Delta x_{l i j t}, \Delta x_{l i j t}\right) ; \\
& x_{2 i}=\left(\Delta x_{l i j t}, \Delta x_{2 i j t}, \Delta x_{2 i j t}\right) ; \\
s_{i}{ }^{*} & \left.=\Delta c_{i j t} \text { if a participant household; and } s^{*}{ }_{i}=g \text { (constant, } g<\Delta c_{i j t}\right) \text { otherwise. } \\
& \text { The equations (3) and (4) now become the following: } \\
y_{i}= & x_{1 i} \beta_{1}+\varepsilon_{1 i} \\
s_{i}^{*}= & x_{2 i} \beta_{2}+\varepsilon_{2 i}
\end{aligned}
$$$$
x_{2 i}=\left(\Delta x_{i j i j}, \Delta x_{2 i j t}, \Delta x_{2 i j t}\right) \text {; }
$$$$
\text { The equations ( } 3 \text { ) and (4) now become the following: }
$$

Equation (5) represents the household welfare and equation (6) indicates the exclusion propensity. Thus, $y_{i}$ is the observed welfare for household $i$ if it is a participant household and $s_{i}^{*}$ is a latent variable that indicates the propensity to be a participant household. Vectors $x_{1 i}$ and $x_{2 i}$ are vectors of observed explanatory variables; $\varepsilon_{1 i}$ and $\varepsilon_{2 i}$ 
are mean-zero stochastic errors representing the influence of unobserved variables affecting $y_{i}$ and $s_{i}{ }_{i}$. The parameters of interest are $\beta_{1}$ and $\beta_{2}$.

Since the latent variable $s_{i}^{*}$ is unobserved, we define a dummy variable:

$s_{i}=1$ if $s_{i}^{*}>g$

$s_{i}=0$ if otherwise.

We thus observe the welfare of participant households only if $s_{i}=1$, i.e., if the households borrow at both times, $t$ and $t+1$. It is likely that the unobserved terms $\varepsilon_{l i}$ and $\varepsilon_{2 i}$ are correlated: households with lower welfare, the poorer, given $x_{1 i}$ and $x_{2 i}$, are more likely to want to be participant households. If so, the sample of participant households observed will not accurately represent the underlying population. Hence, inappropriate selection of samples for study generally produces inconsistent estimates of the parameters in the welfare equation.

To solve the sample selection problem, we follow the Heckman (1979) approach, which suggested a simple method to deal with this selection problem. The conditional mean of $\varepsilon_{l i}$ can be written as follows ${ }^{1}$ :

$$
E\left(\varepsilon_{1 i} \mid s_{i}^{*}>0\right)=E\left(\varepsilon_{1 i} \mid \varepsilon_{2 i}>-x_{2 i} \beta_{2}\right)
$$

and hence

$$
E\left(y_{1 i} \mid x_{1 i}, s_{i}=1\right)=x_{1 i} \beta_{1}+E\left(\varepsilon_{1 i} \mid \varepsilon_{2 i}>-x_{2 i} \beta_{2}\right)
$$

Equation (8) shows that the regression equation on the selected sample depends on both $x_{1 i}$ and $x_{2 i}$. Omitting the conditional mean of $\varepsilon_{1 i}$ biases the estimates of $\beta_{1}$ unless $\varepsilon_{1 i}$ and $\varepsilon_{2 i}$ are uncorrelated. Selection bias can thus be regarded as a standard problem of omitted-variable bias. The solution is to find an empirical representation of the conditional mean of $\varepsilon_{l i}$ and includes this variable in the welfare equation.

Under the assumption that $\varepsilon_{1 i}$ and $\varepsilon_{2 i}$ are drawn from a bivariate normal distribution, we can derive the regression equation:

$$
E\left(y_{1 i} \mid x_{1 i}, s_{i}=1\right)=x_{1 i} \beta_{1}+\rho \sigma_{1} \lambda_{i}
$$

where $\rho$ is the correlation coefficient between $\varepsilon_{1 i}$ and $\varepsilon_{2 i}, \sigma_{1}$ is the standard deviation of $\varepsilon_{l i}$, and $\lambda_{i}$ is the inverse of Mill's ratio (see Greene, 2003), which is given by:

$$
\lambda_{i}=\frac{\phi\left(x_{2 i} \beta_{2} / \sigma_{2}\right)}{\Phi\left(x_{2 i} \beta_{2} / \sigma_{2}\right)}
$$

where $\phi$ and $\Phi$ are the density and distribution functions of the standard normal distribution and $\sigma_{2}$ is the standard deviation of $\varepsilon_{2 i}$.

The Heckman approach suggests estimation of (8) in a two-step procedure. The first step involves estimating the parameters in (6) by the Probit method, using the entire sample. These estimates can then be used to compute $\lambda_{i}$ for each household in the sample. Once $\lambda_{i}$ is computed, we can estimate (5) over the sample of participant households by ordinary least squares regression, treating $\rho \sigma_{l}$ as the regression coefficient for $\lambda_{i}$.

\section{The integrated model}

\footnotetext{
${ }^{1}$ For simplicity, we include an intercept in $x_{2}$ and hence we can normalize $g$ to 0 .
} 
Having paid attention to both the problem of endogenous credit and sample selection bias, the integrated model can be estimated as follows. The first step involves estimating the parameters in (6) by the Probit method, using the entire sample. The inverse Mill's ratio $\lambda_{i}$ is then calculated for each household. The second step involves estimating the parameters in (3) by the least squares method, using a sample of participant households. The predicted value of credit and the predicted residual are then calculated for each household. The last step involves estimating the parameters in (4) by the least squares method, using the participant households and the predicted value of credit instead of the true value. The predicted residual and the inverse Mill's ratio are included as the explanatory variables to control for endogenous credit and sample selection bias.

\section{DATA AND MEASUREMENT}

Our data is drawn from two surveys on living standards in Vietnam in 1993 (Survey 1) and 1998 (Survey 2). These two surveys were the first of their type in Vietnam and conducted with technical assistance from international organizations. We choose these two surveys because we believe they are more reliable than the later surveys for the purpose of this paper as they provide a wider coverage across the rural areas in the country. This reduces greatly the possibility of sample selection bias to some extent.

Survey 1 covers a sample of 4,799 households, 150 communes and 300 villages over the country. There are 3,839 rural households, accounting for $80 \%$ of the overall sample. Of the rural households, there are 1,985 households (41.4\%) holding debt from various sources. Survey 2 was designed to provide an up-to-date source of data on households. It covers a sample of 5,999 households, 194 communes and 388 villages, including all households surveyed in Survey 1. The proportion of rural households is $71.2 \%$ (4,269 households). $38.9 \%$ of rural households borrow from one source or another. The timing of the second survey approximately five years after the first facilitates the analysis of medium term trends in living standards.

The construction of variables is an important and complicated part of our methodology. As we have mentioned in the model section, we consider the change or time difference between values in Survey 2 and Survey 1. As a result, any variable should be understood as the difference estimator.

Following this construction, the groups of variables are considered as follows. The dependent variables, which proxy for household welfare, include per capita expenditure, per capita food expenditure, per capita non-food expenditure and household poverty status in logarithm form. These variables are considered in the form of difference estimators. The household poverty status is a dummy variable where if the household improves its poverty classification, which is given by the survey, between the two surveys, the dependent variable takes the value of 1 , and otherwise 0 . The explanatory variables of interest including formal borrowing, informal borrowing and total household borrowing, are constructed by the sum of all loans from the formal, informal and both sources respectively. The differenced variables are then computed by calculating the difference in borrowing (in logarithm form) between Survey 2 and Survey 1.

The household characteristics include variables of natural attributes such as age, gender of household head, farm household; and variables of household assets such as savings and farm-land owning in differenced variable form. For the differenced variable 
of the age of the household head, we look at the age groups (i.e. the first digit of the actual age) and therefore we avoid the problem of the same differenced variables of age for every household head. The differenced variables of gender of the household head and the type of business are constructed as dummy variables. The dummy variable of gender takes the value of 1 if the household head is male in Survey 2 but female in Survey 1 (i.e. the household head died between two surveys), and 0 otherwise. The dummy variable of farm household takes the value of 1 if the household is a farm household in Survey 2, but non-farm household in Survey 1 i.e. new farm household, and 0 otherwise.

The local market characteristic variables include: the prices of selected goods and services; the averaged household characteristics in a commune, such as averaged education, and averaged farm-land owning. All are in the form of differenced variables which are calculated by taking the difference between values (in logarithm form) in Survey 2 and Survey 1 . The construction of variables of local market characteristics is mainly for the purpose of control for the location fixed effects, rather than for comparison. The lender characteristics include proxy variables, in differenced variable form, of the availability of funds at commune and village levels and the competition between lenders. We consider the availability of both formal and informal funds to control for the competition between these two sources of funds within the same location. The descriptive variables are presented in Table 1.

[Insert Table 1 about here]

\section{ECONOMETRIC PROCEDURE AND RESULTS}

In this section, we implement the three stage regression analysis. The first stage estimates the probability of a household being a participant household i.e. borrowing again in the second period. The second stage is to control for the endogenous credit by estimating the factors that affect the change in the amount of borrowing for the participant households. In the third stage, the inverse Mill's ratios and the predicted residuals, which result from the first stage and the second stage, are included as explanatory variables to control for the sample selection bias and the endogeneity of credit in the estimation of household welfare. The regression procedure is implemented for three samples formal, informal and total borrowing.

[Insert Table 2 about here]

Table 2 presents the results from first stage regression. Of the household characteristics, a household tends not to borrow in the second period when the household head becomes older; they shift their business to farm activities; or they have savings. More interestingly, the results indicate that there is a competition between formal and informal lenders and that in order to help rural households gain access to formal credit, the credit network must be extended at village level.

\section{[Insert Table 3 about here]}

Table 3 shows the second stage. Among other results, we see that more education may result in reducing the demand for household borrowing and that more educated households are reluctant to borrow from informal lenders. Interestingly, we find no evidence for the use of farmland ownership as a screening criteria for loans. And 
again, we find the availability of funds at village level is an important influence on household borrowing.

[Insert Tables 4, 5, 6, 7, 8 about here]

Table 4 shows the existence of the sample selection bias and the endogeneity of credit. We only include the predicted residuals and inverse Mill's ratios in the third stage regressions if they are found significant. Tables from 5 to 8 report the third stage regressions and all suggest that the change in the amount of household borrowing is positively and significantly related to the change in household welfare as measured by per capita expenditure, per capita food expenditure, per capita non-food expenditure and household poverty status, at a sufficiently small level of significance. The results also indicate that both formal and informal credit have positive and significant effects on household welfares. Furthermore, our results suggest that formal credit has a slightly higher impact than informal credit. Although the proxies for household welfares are different, our conclusions are similar to those of Lensink and Pham (2012), Doan et al (2014), and Tran et al (2015). One may interpret this finding to mean that the growth in household borrowing relates to the growth in household welfare, and thus reflects the long-run impact of credit on household welfare. However, the coefficients of the relationship are found to be small. This raises the issue of cost-benefit analysis.

\section{CONCLUSIONS}

In this paper, we have presented an econometric framework for estimating the long-term impact of credit on households, using panel data from household surveys. Our econometric procedure takes into account the problems of sample selection bias and endogenous credit (Pitt and Khandker, 1998, Coleman, 1999). We employ a three stage regression: the first stage controls for the sample selection bias; the second stage controls for the endogeneity of credit; and the third stage is to estimate the credit impact on household welfare, where the inverse Mill's ratios and the predicted residuals, which are computed from the first and second stages, are included as explanatory variables.

We find that credit has a long-term positive and significant impact on household welfare at the $1 \%$ level of significance. Our findings confirm the conclusions widely cited in the literature (Khandker, 1998, 2001, 2003; Pitt and Khandker, 1998; Coleman, 2002; Karlan and Zinman, 2010; Augsburg et al, 2014; Angelucci et al, 2015; Banerjee et al, 2015) and in Vietnam (Lensink and Pham, 2012; Doan et al, 2014; and Tran et al, 2015). The findings also indicate that both formal and informal credit contributes to household welfares and that formal credit has a relatively higher impact than informal credit. This conclusion is a bit different with Doan et al (2014), which does not suggest the role of informal credit. This finding indicates that providing credit to the poor has a positive impact on household poverty reduction. We also conclude that there is competition between formal and informal credit in rural areas at village level and in order to help rural households gain more access to credit, the credit network must be extended to the village level.

However, we should be concerned about the low impact of credit on household welfare. Given the high costs of providing credit to rural households, the benefit (i.e. the impact) may be lower than the cost, and hence the question is raised: should we provide 
credit on a risk-related or a subsidized basis?. Moreover, credit is not the only tool in a poverty reduction strategy, so why do we need to supply cheap credit? We however leave these questions for future research. 


\section{REFERENCES}

Angelucci, M., Karlan, D. and Zinman, J. (2015). "Microcredit Impacts: Evidence from a Randomized Microcredit Program Placement Experiment by Compartamos Banco", American Economic Journal: Applied Economics, Vol. 7, pp. 151-82.

Augsburg, B., De Haas, R., Harmgart, H., and Meghir, Co. (2014), "The Impacts of Microcredit: Evidence from Bosnia and Herzegovina", American Economic Journal: Applied Economics, Vol. 7, pp. 183-203.

Banerjee, A.,V., Duflo, E., Glennerster, R., and Kinnan, C. (2015), "The Miracle of Microfinance? Evidence from a Randomized Evaluation", American Economic Journal: Applied Economics, Vol. 7, pp. 22-53.

Barsland, M., and Tarp, F. (2008), "Formal and informal credit in four provinces of Vietnam", Journal of Development Studies, Vol. 44, No. 4, 485-503.

Coleman B. (1999), "The impact of group lending in Northeast Thailand", Journal of Development Economics, Vol. 60, pp. 105-141.

Coleman, B. E. (2002), "Microfinance in Northeast Thailand: Who benefits and How much?", Working paper, Asian Development Bank, Economics and Research Department, No. 9.

Doan, T., Gibson, J., and Holmes, M. (2014), "Impact of Household Credit on Education and Healthcare Spending by the Poor in Peri-Urban Areas, Vietnam", Journal of Southeast Asian Economies Vol. 31, No. 1, pp. 87-103.

Hausman, J. A. (1978), "Specification Tests in Econometrics", Econometrica, Vol. 46, No.6, pp. 1251-1271.

Heckman J. (1974), "Shadow Prices, market wages and labour supply", Econometrica, Vol. 44, pp. 679-94 .

Heckman, J. (1979), "Sample Selection Bias as a Specification Error", Econometrica, Vol. 47, pp. 153-161.

Karlan, D., and Zinman, J. (2010), "Expanding Credit Access: Using Randomized Supply Decisions to Estimate the Impacts", Review of Financial Studies, Vol. 23, pp. 433-464.

Khandker, S. R. (1998), Fighting Poverty with Microcredit: Experience in Bangladesh, New York: Oxford University Press, Inc.

Khandker, S. R. (2001). "Does Micro-finance Really Benefit the Poor? Evidence from Bangladesh", Asia and Pacific Forum on Poverty: Reforming Policies and Institutions for Poverty Reduction, Manila: Asian Development Bank.

Khandker, S. R. (2003), "Microfinance and Poverty: Evidence Using Panel Data from Bangladesh", Working paper, World Bank Policy Research, No. 2945.

Khandker, S.R., and R.R. Faruqee (2003), "The impact of farm credit in Pakistan", Journal of Agricultural Economics, Vol. 28, pp. 197-213.

Lensink, R., and Pham, T., T., T. (2012), "The impact of microcredit on self-employment profits in Vietnam", Economics of Transition, Vol. 20, No. 1, pp. 73-111.

Nghiem, S., Coelli, T., and Rao, P. (2012), "Assessing the Welfare Effects of Microfinance in Vietnam: Empirical Results from a Quasi-Experimental Survey", Journal of Development Studies, Vol. 48, No. 5, pp. 619-632. 
Pham, B.D. and Izumida, Y. (2002), "Rural development finance in Vietnam: a microeconometric analysis of household surveys", World Development, Vol. 30, No.2, 319-335.

Pitt, M., and S., Khandker (1998), "The impact of group-based credit programs on poor households in Bangladesh: Does the gender of participants matter?", Journal of Political Economy, Vol. 106, 958-995.

Robinson, M. (2001) The microfinance revolution: Sustainable finance for the poor, Washington, DC: World Bank.

Tran T. G., Wang G., and Nguyen, D.C. (2015), "Impact of Credit on Poor Household's Income: Evidence from Rural Areas of Vietnam", Journal of Finance and Economics, Vol. 3, No. 2, 29-35. 
TABLE 1 - DESCRIPTIVE STATISTICS FOR ALL VARIABLES USED IN THIS STUDY

Change in total household borrowing (Log of S2/S1 $1^{+}$, VND1000)

Change in formal borrowing ( $\log$ of S2/S1, VND1000)

Change in ifor

Change in infor

Increase in per capita expenditure (Log of S2/S1, VND1000)

Change in per capita non-food expenditure (Log of S2/S1, VND1000)

Dummy: if poverty status changes

Change in age group of household head

Change in education of household head (years)

Dummy: if household becomes farm household

Dummy: if household head becomes male

Change in household size (persons)

Change in ownership of farming land (Log of S2/S1, hectare)

Change in financial savings (Log of S2/S1, VND1000)

Change in non-financial savings (Log of S2/S1, VND1000)

Change in price of detergent ( $\log$ of S2/S1, VND1000/kg)

Change in price of fish sauce (Log of S2/S1, VND1000/bottle)

Change in price of noodles (Log of S2/S1, VND1000/pack)

Change in price of pork (Log of S2/S1, VND1000/kg)

Change in price of ordinary rice $(\log$ of $\mathrm{S} 2 / \mathrm{S} 1, \mathrm{VND} 1000 / \mathrm{kg})$

Change in price of sewing service (Log of S2/S1, VND1000/trouser)

Change in averaged education of household head in commune (years)

Change in averaged ownership of farming land in commune (Log of S2/S1,

hectare)

Change in number of households in commune (households)

Change in price index of the region

Change in the availability of informal fund in village (Log of S2/S1, VND1000)

Change in the availability of formal fund in village (Log of S2/S1, VND1000)

Change in availability of formal funds in commune (Log of S2/S1, VND1000)

\begin{tabular}{|c|c|c|c|c|c|}
\hline Mean & Median & Maximum & Minimum & Std. Dev. & Observations \\
\hline 1.258727 & 1.337696 & 5.298317 & -6.21461 & 1.311738 & 970 \\
\hline 1.659879 & 0.77174 & 10.4631 & -9.6486 & 4.470119 & 970 \\
\hline-0.18709 & 0 & 10.45109 & -10.0858 & 4.351428 & 970 \\
\hline 0.684143 & 0.677341 & 2.22729 & -1.0513 & 0.440623 & 970 \\
\hline 0.607207 & 0.60202 & 2.664455 & -1.35539 & 0.433719 & 970 \\
\hline 0.826015 & 0.829054 & 3.115618 & -2.11796 & 0.671965 & 970 \\
\hline 0.310309 & 0 & 1 & 0 & 0.462859 & 970 \\
\hline 0.298969 & 0 & 5 & -5 & 1.012461 & 970 \\
\hline 0.564948 & 0 & 16 & -11 & 2.330842 & 970 \\
\hline 0.048454 & 0 & 1 & 0 & 0.214834 & 970 \\
\hline 0.021649 & 0 & 1 & 0 & 0.145611 & 970 \\
\hline-0.17835 & 0 & 5 & -11 & 1.613969 & 970 \\
\hline-0.95095 & -0.72157 & 9.10498 & -11.0021 & 2.670397 & 970 \\
\hline 3.260722 & 4.068698 & 9.615805 & -7.6009 & 3.192478 & 970 \\
\hline 1.066843 & 0 & 11.0021 & -10.309 & 4.025281 & 970 \\
\hline-0.09198 & -0.05711 & 2.169054 & -0.87467 & 0.447066 & 970 \\
\hline 0.633214 & 0.559616 & 2.197225 & -0.80968 & 0.572161 & 970 \\
\hline 0.314333 & 0.287682 & 0.972861 & -0.18232 & 0.193624 & 970 \\
\hline 0.444679 & 0.446287 & 0.899758 & 0.162519 & 0.142338 & 970 \\
\hline 0.66744 & 0.67634 & 1.052818 & 0.153492 & 0.170443 & 970 \\
\hline 0.777575 & 0.693147 & 1.734601 & 0 & 0.413172 & 970 \\
\hline 0.039763 & 0.04 & 1.83 & -2.72 & 0.781263 & 970 \\
\hline-0.83698 & -0.9065 & 7.8 & -2.578 & 1.00587 & 970 \\
\hline-978.647 & -823 & 247 & -4154 & 665.7434 & 970 \\
\hline 0.012842 & 0.025835 & 0.099597 & -0.08317 & 0.036564 & 970 \\
\hline 0.545066 & 0.793092 & 8.941153 & -10.3156 & 2.297871 & 970 \\
\hline 1.813926 & 1.711221 & 11.12726 & -9.16952 & 3.239065 & 970 \\
\hline 1.4932 & 1.691676 & 9.87817 & -8.90463 & 2.484622 & 970 \\
\hline
\end{tabular}

Note: Log of $S 2 / S 1=$ value in Survey 2 divided by value in Survey 1 in logarithm form = value in Survey 2 in logarithm form - value in Survey 1 in logarithm form. 
TABLE 2 - FIRST STAGE REGRESSION

\begin{tabular}{|c|c|c|c|c|c|c|c|c|c|}
\hline & & & Formal & & & Informal & & & Total \\
\hline Change in age group of household head & -0.059868 & -1.008687 & 0.3131 & 0.028096 & 0.629145 & 0.5293 & -0.082077 & -2.138169 & 0.0325 \\
\hline Change in education of household head (years) & -0.005059 & -0.195974 & 0.8446 & 0.017723 & 0.950480 & 0.3419 & -0.001082 & -0.067941 & 0.9458 \\
\hline Dummy: if household becomes farm household & -0.494563 & -2.141800 & 0.0322 & -0.059175 & -0.343427 & 0.7313 & -0.279612 & -1.944081 & 0.0519 \\
\hline Change in ownership of farming land (hectare) & 0.029302 & 1.212080 & 0.2255 & 0.028425 & 1.622342 & 0.1047 & 0.007632 & 0.531862 & 0.5948 \\
\hline Change in financial savings (VND1000) & -0.004807 & -0.279889 & 0.7796 & -0.050172 & -3.808391 & 0.0001 & -0.028600 & -2.532805 & 0.0113 \\
\hline Change in non-financial savings (VND1000) & -0.019953 & -1.424060 & 0.1544 & -0.041818 & -4.009752 & 0.0001 & -0.031903 & -3.697330 & 0.0002 \\
\hline Change in price of pork (VND1000/kg) & 0.509921 & 1.180660 & 0.2377 & 0.613708 & 1.990966 & 0.0465 & 0.221996 & 0.862429 & 0.3885 \\
\hline Change in price of ordinary rice (VND1000/kg) & -0.534641 & -1.464423 & 0.1431 & 0.096637 & 0.359823 & 0.7190 & -0.489018 & -2.202483 & 0.0276 \\
\hline Change in price of sewing service (VND1000/trouser) & 0.102569 & 0.696204 & 0.4863 & -0.176573 & -1.589655 & 0.1119 & 0.007040 & 0.076510 & 0.9390 \\
\hline Change in averaged education of household head in commun & 0.014639 & 0.172747 & 0.8629 & 0.045636 & 0.772939 & 0.4396 & -0.001858 & -0.038137 & 0.9696 \\
\hline amune (hectare) & -0.176221 & -2.462660 & 0.0138 & -0.060181 & -1.496800 & 0.1344 & -0.051199 & -1.537817 & 0.1241 \\
\hline Change in number of households in commune (households) & -0.000181 & -2.019783 & 0.0434 & $-8.45 \mathrm{E}-05$ & -1.420133 & 0.1556 & $-2.55 \mathrm{E}-05$ & -0.493214 & 0.6219 \\
\hline Change in price index of the region & -3.749966 & -2.197629 & 0.0280 & -1.025642 & -0.849724 & 0.3955 & -2.407694 & -2.354277 & 0.0186 \\
\hline McFadden R-squared & 0.123162 & & & 0.105810 & & & 0.034713 & & \\
\hline Log likelihood & -393.6199 & & & -683.5210 & & & -956.3288 & & \\
\hline LR statistic (21 df) & 110.5768 & & & 161.7620 & & & 68.78238 & & \\
\hline Probability(LR stat) & 3.71E-14 & & & 0.000000 & & & $5.50 \mathrm{E}-07$ & & \\
\hline Total obs & 649 & & & 1128 & & & 1516 & & \\
\hline Obs with $\mathrm{Dep}=1$ & 307 & & & 465 & & & 970 & & \\
\hline
\end{tabular}


TABLE 3 - SECOND STAGE REGRESSION

\begin{tabular}{|c|c|c|c|c|c|c|c|c|c|}
\hline & & & Formal & & & Informal & & & Total \\
\hline Change in age group of household head & -0.003035 & -0.049809 & 0.9603 & -0.039864 & -0.571683 & 0.5678 & -0.035905 & -0.804680 & 0.4212 \\
\hline Change in education of household head (years) & -0.016087 & -0.565388 & 0.5723 & -0.073221 & -2.431726 & 0.0154 & -0.044742 & -2.282449 & 0.0227 \\
\hline Dummy: if household becomes farm household & -0.512816 & -1.798786 & 0.0731 & -0.188381 & -0.664380 & 0.5068 & -0.353820 & -1.817413 & 0.0695 \\
\hline Change in household size (persons) & 0.056545 & 1.722983 & 0.0860 & 0.063182 & 1.444721 & 0.1492 & 0.052008 & 2.005694 & 0.0452 \\
\hline Change in ownership of farming land (hectare) & -0.018009 & -0.714277 & 0.4756 & 0.001922 & 0.067899 & 0.9459 & -0.007746 & -0.453572 & 0.6502 \\
\hline Change in financial savings (VND1000) & 0.040916 & 2.333062 & 0.0203 & 0.019008 & 0.930748 & 0.3525 & 0.046507 & 3.461918 & 0.0006 \\
\hline Change in non-financial savings (VND1000) & 0.026722 & 1.890427 & 0.0597 & -0.004519 & -0.257716 & 0.7967 & -0.002149 & -0.201687 & 0.8402 \\
\hline Change in price of pork (VND1000/kg) & -0.876607 & -2.040432 & 0.0422 & -0.271778 & -0.539364 & 0.5899 & 0.034437 & 0.111440 & 0.9113 \\
\hline Change in price of ordinary rice (VND1000/kg) & 0.201898 & 0.513618 & 0.6079 & -0.273154 & -0.617563 & 0.5372 & -0.294298 & -1.087352 & 0.2772 \\
\hline Change in price of sewing service (VND1000/trouser) & 0.029579 & 0.181961 & 0.8557 & 0.089821 & 0.503526 & 0.6148 & -0.041748 & -0.364011 & 0.7159 \\
\hline Change in averaged education of household head ir & 0.024614 & 0.283242 & 0.7772 & 0.003105 & 0.032704 & 0.9739 & -0.056421 & -0.948658 & 0.3430 \\
\hline Change in averaged ownership of farming land in commune (hectare) & -0.118392 & -1.328967 & 0.1849 & -0.070533 & -0.997951 & 0.3188 & -0.029904 & -0.655411 & 0.5124 \\
\hline of households in commune (hou & $3.48 \mathrm{E}-05$ & 0.333381 & 0.7391 & $-1.45 \mathrm{E}-05$ & 706 & 0.8787 & 127 & 1.877255 & 0.0608 \\
\hline Change in price index of the region & 2.603701 & 1.494464 & 0.1362 & 1.017354 & 0.516302 & 0.6059 & -0.221518 & -0.175279 & 0.8609 \\
\hline Adjusted R-squared & 0.288381 & & & 0.040217 & & & 0.045355 & & \\
\hline F-statistic & 6.905032 & & & 1.925845 & & & 3.192237 & & \\
\hline Prob(F-statistic) & 0.000000 & & & 0.008496 & & & 0.000002 & & \\
\hline Log likelihood & -400.0566 & & & -785.9999 & & & -1605.945 & & \\
\hline Durbin-Watson stat & 2.885498 & & & 2.049768 & & & 2.071620 & & \\
\hline Number of observations & 307 & & & 465 & & & 970 & & \\
\hline
\end{tabular}


TABLE 4 - TESTS OF SAMPLE SELECTION BIAS AND ENDOGENEITY OF CREDIT

\begin{tabular}{|c|c|c|c|c|c|c|}
\hline & $\begin{array}{r}\text { Formal } \\
\text { t-statistics }\end{array}$ & Prob. & $\begin{array}{r}\text { Informal } \\
\text { t-statistics }\end{array}$ & Prob. & $\begin{array}{r}\text { Total } \\
\text { t-statistics }\end{array}$ & Prob \\
\hline \multicolumn{7}{|l|}{ Per capita expenditure } \\
\hline Predicted residuals & -0.168346 & 0.8664 & -1.207697 & 0.2278 & -3.250263 & $0.0012 *$ \\
\hline Inverse Mill's ratios & 2.184167 & $0.0298 *$ & 1.577784 & 0.1153 & 1.936737 & $0.0531 * *$ \\
\hline \multicolumn{7}{|c|}{ Per capita food expenditure } \\
\hline Predicted residuals & 0.388623 & 0.6978 & -1.073712 & 0.2835 & -2.227034 & $0.0262 *$ \\
\hline Inverse Mill's ratios & 1.506197 & 0.1331 & 1.500872 & 0.1341 & 0.098025 & 0.9219 \\
\hline \multicolumn{7}{|c|}{ Per canita non-food expenditure } \\
\hline Predicted residuals & -0.898350 & 0.3698 & -1.199850 & 0.2308 & -2.848845 & $0.0045^{*}$ \\
\hline Inverse Mill's ratios & 2.367454 & $0.0186^{*}$ & 1.030706 & 0.3032 & 2.290689 & $0.0222 *$ \\
\hline \multicolumn{7}{|c|}{ Change in household poverty status } \\
\hline Predicted residuals & -0.270719 & 0.7866 & -0.797482 & 0.4252 & -1.638231 & 0.1014 \\
\hline Inverse Mill's ratios & 1.342636 & 0.1794 & 1.044812 & 0.2961 & 0.782798 & 0.4337 \\
\hline
\end{tabular}

* Significant at $5 \%$

** Significant at $10 \%$

Note: Significant at $10 \%$ indicating that the control of endogenous credit and sample selection bias is necessary.

The test of predicted residuals indicates Durbin-Wu-Hausman test. 
TABLE 5 - THIRD STAGE REGRESSION: PER CAPITA EXPENDITURE

\begin{tabular}{|c|c|c|c|c|c|c|c|c|c|}
\hline & & & Formal & & & Informal & & & Total \\
\hline Change in age group of household head & -0.002194 & -0.093832 & 0.9253 & 0.023776 & 1.238121 & 0.2163 & 0.013132 & 0.773420 & 0.4395 \\
\hline Change in education of household head (years) & 0.009087 & 0.853351 & 0.3942 & 0.002979 & 0.356495 & 0.7216 & 0.013310 & 1.995201 & 0.0463 \\
\hline Dummy: if household becomes farm household & -0.194841 & -1.674559 & 0.0951 & -0.073383 & -0.931849 & 0.3519 & -0.048351 & -0.734803 & 0.4626 \\
\hline Change in household size (persons) & -0.094226 & -7.416255 & 0.0000 & -0.091289 & -7.583252 & 0.0000 & -0.096559 & -11.59023 & 0.0000 \\
\hline Change in ownership of farming land (hectare) & 0.029143 & 3.029618 & 0.0027 & -0.002068 & -0.264629 & 0.7914 & 0.002394 & 0.449165 & 0.6534 \\
\hline Change in financial savings (VND1000) & 0.015196 & 2.236452 & 0.0261 & 0.013070 & 2.324764 & 0.0205 & -0.004234 & -0.520448 & 0.6029 \\
\hline Change in non-financial savings (VND1000) & 0.004317 & 0.776476 & 0.4381 & 0.004246 & 0.889887 & 0.3740 & 0.002929 & 0.523526 & 0.6007 \\
\hline Change in price of pork (VND1000/kg) & 0.193292 & 1.203187 & 0.2299 & 0.027116 & 0.197326 & 0.8437 & 0.152356 & 1.526267 & 0.1273 \\
\hline Change in price of ordinary rice (VND1000/kg & -0.129909 & -0.801953 & 0.4232 & -0.197759 & -1.628366 & 0.1041 & -0.008588 & -0.091258 & 0.9273 \\
\hline Change in price of sewing service (VND1000/trou & 0.143664 & 2.592270 & 0.0100 & 0.247381 & 5.261577 & 0.0000 & 0.184266 & 5.760036 & 0.0000 \\
\hline aged education of household he & -0.012954 & -0.399927 & 0.6895 & 0.012695 & 0.498322 & 0.6185 & 0.039722 & 2.227464 & 0.0262 \\
\hline Change in averaged ownership of farming land & -0.051236 & -1.380018 & 0.1687 & 0.000801 & 0.041481 & 0.9669 & 0.007608 & 0.497559 & 0.6189 \\
\hline Change in price index of the region & -3.733759 & -5.631919 & 0.0000 & -1.477565 & -2.888825 & 0.0041 & -3.029959 & -5.705976 & 0.0000 \\
\hline Change in total household borrowing (VND1000) & 0.059048 & 2.784477 & 0.0057 & 0.030094 & 2.328712 & 0.0203 & 0.276427 & 3.587656 & 0.0004 \\
\hline F-statistic & 8.207945 & & & 8.182273 & & & 17.16219 & & \\
\hline Prob (F-statistic) & 0.000000 & & & 0.000000 & & & 0.000000 & & \\
\hline Log likelihood & -105.9159 & & & -194.5800 & & & -431.1583 & & \\
\hline Durbin-Watson s & 3.002922 & & & 1.572069 & & & 1.957169 & & \\
\hline Number of observations & 307 & & & 465 & & & 970 & & \\
\hline
\end{tabular}


TABLE 6 - THIRD STAGE REGRESSION: PER CAPITA FOOD EXPENDITURE

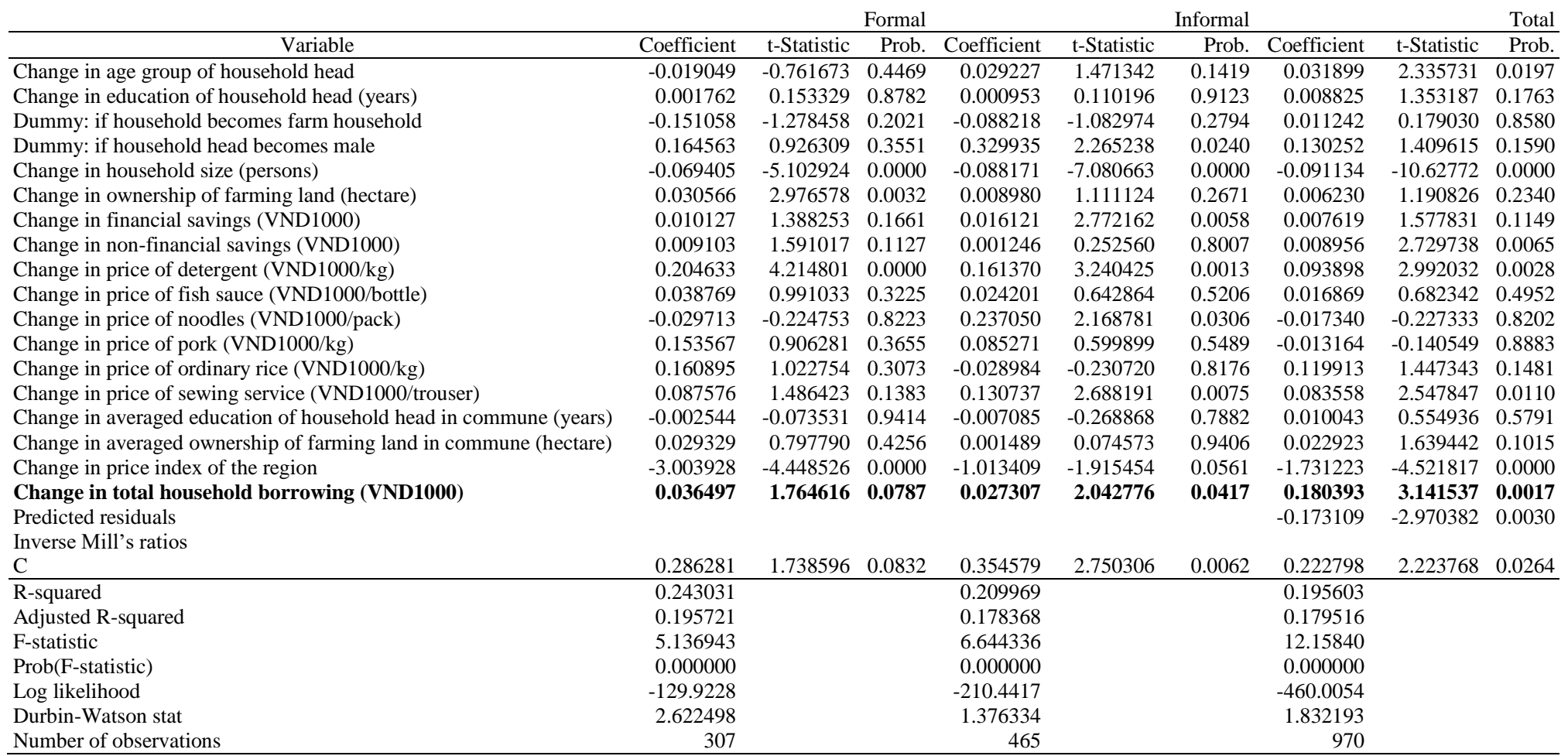

Number of observations 
TABLE 7 - THIRD STAGE REGRESSION: PER CAPITA NON-FOOD EXPENDITURE

\begin{tabular}{|c|c|c|c|c|c|c|c|c|c|}
\hline & & & Formal & & & Informal & & & Total \\
\hline Variable & Coefficient & t-Statistic & Prob. & Coefficient & t-Statistic & Prob. & Coefficient & t-Statistic & Prob. \\
\hline Change in age group of household head & 0.025572 & 0.690383 & 0.4905 & 0.015677 & 0.504073 & 0.6145 & -0.009119 & -0.335741 & 0.7371 \\
\hline Change in education of household head (years) & 0.012511 & 0.741687 & 0.4589 & 0.005527 & 0.408397 & 0.6832 & 0.019570 & 1.833870 & 0.0670 \\
\hline Dummy: if household becomes farm household & -0.106984 & -0.580427 & 0.5621 & -0.087468 & -0.685835 & 0.4932 & -0.123646 & -1.174648 & 0.2404 \\
\hline Change in ownership of farming land (hectare) & 0.027619 & 1.812472 & 0.0710 & -0.011921 & -0.942199 & 0.3466 & 0.001317 & 0.154432 & 0.8773 \\
\hline Change in financial savings (VND1000) & 0.025631 & 2.381154 & 0.0179 & 0.013811 & 1.516886 & 0.1300 & -0.012961 & -0.995903 & 0.3196 \\
\hline Change in non-financial savings (VND1000) & 0.002450 & 0.278177 & 0.7811 & 0.004837 & 0.625970 & 0.5317 & -0.001580 & -0.176544 & 0.8599 \\
\hline Change in price of detergent (VND1000/kg) & 0.107384 & 1.488764 & 0.1376 & 0.126201 & 1.618645 & 0.1062 & 0.100941 & 2.057435 & 0.0399 \\
\hline Change in price of pork (VND1000/kg) & 0.291365 & 1.144894 & 0.2532 & -0.092421 & -0.415294 & 0.6781 & 0.389087 & 2.436580 & 0.0150 \\
\hline rdinary rice (VND1000/kg) & -0.139708 & -0.544428 & 0.5866 & -0.407558 & -2.072170 & 0.0388 & -0.068136 & -0.452584 & 0.6510 \\
\hline Change in price of sewing service (VND1000/trouse & 0.286645 & 3.265014 & 0.0012 & 0.413022 & 5.424305 & 0.0000 & 0.334511 & 6.536592 & 0.0000 \\
\hline dod of boun & -0.002939 & -0.057276 & 0.9544 & 0.049190 & 1.192276 & 0.2338 & 0.099338 & 3.48 & 0.0005 \\
\hline ged ownership of farming land & -0.087693 & -1.491003 & 0.1371 & -0.010113 & -0.323390 & 0.7466 & -0.008087 & -0.330596 & 0.7410 \\
\hline Change in price index of the region & -3.853640 & -3.669361 & 0.0003 & -2.591815 & -3.128959 & 0.0019 & -4.666223 & -5.493135 & 0.0000 \\
\hline Change in total household borrowing (VND1000) & 0.076553 & 2.278827 & 0.0234 & 0.025253 & 1.206615 & 0.2282 & 0.392661 & $\mathbf{3 . 1 8 5 7 3 4}$ & 0.0015 \\
\hline F-statistic & 5.667407 & & & 4.342312 & & & 11.27154 & & \\
\hline Prob(F-statistic) & 0.000000 & & & 0.000000 & & & 0.000000 & & \\
\hline Log likelihood & -247.1467 & & & -420.6909 & & & -886.8798 & & \\
\hline Durbin-Watson sta & 2.587833 & & & 1.583649 & & & 1.895583 & & \\
\hline Number of observations & 307 & & & 469 & & & 970 & & \\
\hline
\end{tabular}

Number of observations 
TABLE 8 - THIRD STAGE REGRESSION: POVERTY STATUS

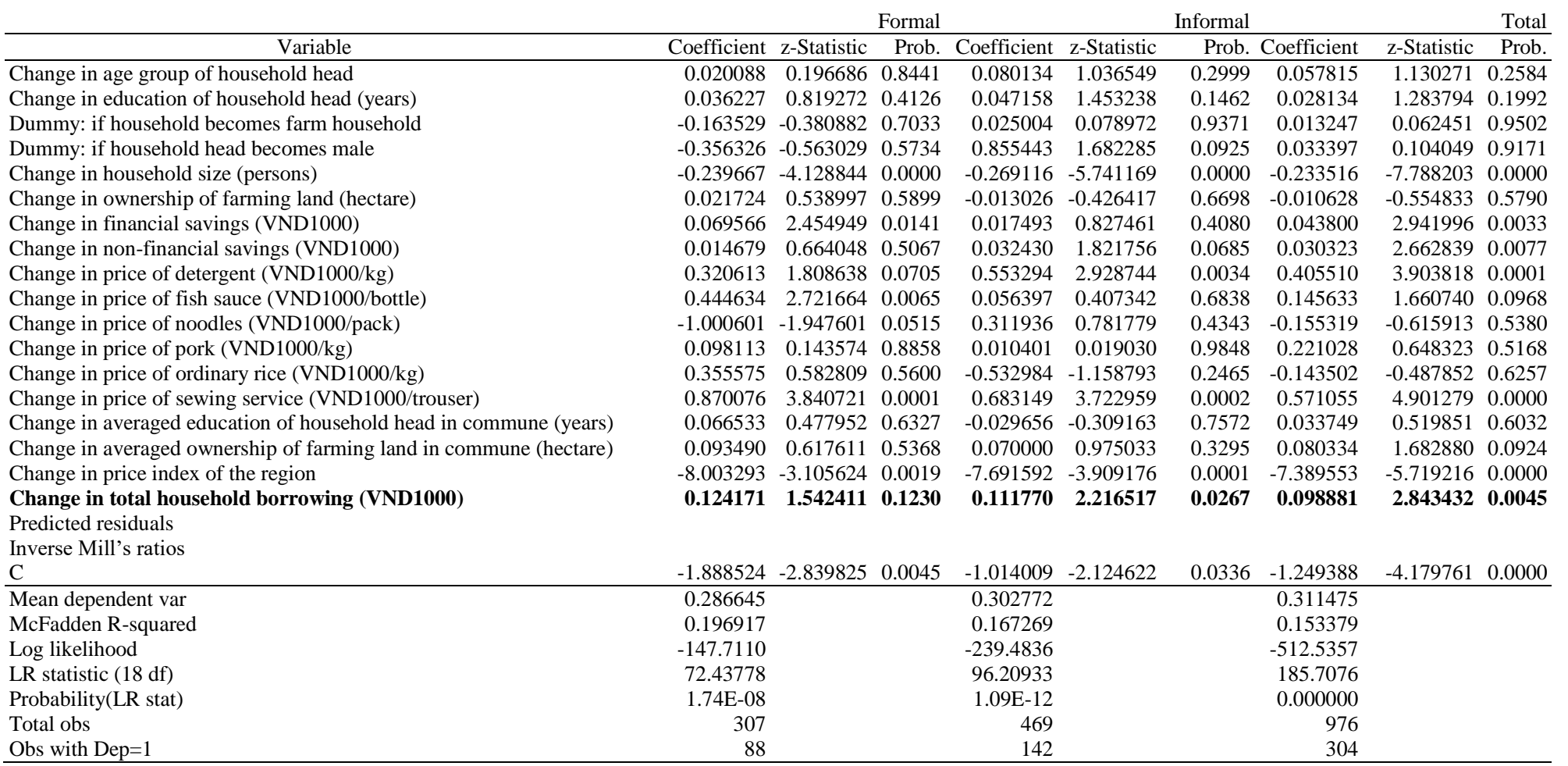

Obs with Dep $=1$ 